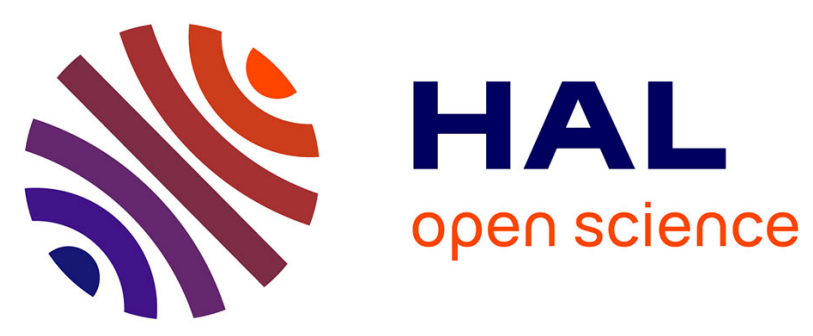

\title{
Deciphering the Crystal Structure of a Scarce 1D Polymeric Thorium Peroxo Sulfate
}

Laura Bonato, Matthieu Virot, Thomas Dumas, Adel Mesbah, Pierre Lecante,

Damien Prieur, X. F Le Goff, Christoph Hennig, Nicolas Dacheux, Philippe

Moisy, et al.

\section{To cite this version:}

Laura Bonato, Matthieu Virot, Thomas Dumas, Adel Mesbah, Pierre Lecante, et al.. Deciphering the Crystal Structure of a Scarce 1D Polymeric Thorium Peroxo Sulfate. Chemistry - A European Journal, 2019, 25 (41), pp.9580-9585. 10.1002/chem.201984163 . hal-02921757

\section{HAL Id: hal-02921757 \\ https://hal.umontpellier.fr/hal-02921757}

Submitted on 15 Dec 2020

HAL is a multi-disciplinary open access archive for the deposit and dissemination of scientific research documents, whether they are published or not. The documents may come from teaching and research institutions in France or abroad, or from public or private research centers.
L'archive ouverte pluridisciplinaire HAL, est destinée au dépôt et à la diffusion de documents scientifiques de niveau recherche, publiés ou non, émanant des établissements d'enseignement et de recherche français ou étrangers, des laboratoires publics ou privés. 


\title{
Deciphering the Crystal Structure of a Scarce 1D Polymeric Thorium Peroxo Sulfate
}

\author{
Laura Bonato, ${ }^{[a]}$ Matthieu Virot, ${ }^{[a]^{*}}$ Thomas Dumas, ${ }^{[b]}$ Adel Mesbah, ${ }^{[a]}$ Pierre Lecante, ${ }^{[c]}$ Damien Prieur, ${ }^{[\mathrm{d}]}$ \\ Xavier Le Goff, ${ }^{[a]}$ Christoph Hennig, ${ }^{[\mathrm{d}]}$ Nicolas Dacheux, ${ }^{\left[{ }^{[a]}\right.}$ Philippe Moisy, ${ }^{[\mathrm{b}]}$ and Sergey I. Nikitenko ${ }^{[\mathrm{a}]}$
}

\begin{abstract}
The preparation and structural characterization of an original Th peroxo sulfate dihydrate crystallizing at room temperature in the form of stable 1D polymeric microfibres is described. A combination of laboratory and synchrotron techniques allowed to solve the structure of $\mathrm{Th}\left(\mathrm{O}_{2}\right)\left(\mathrm{SO}_{4}\right)\left(\mathrm{H}_{2} \mathrm{O}\right)_{2}$ compound which crystallizes in a new structure type in the space group $\mathrm{Pna}_{2}$ of the orthorhombic crystal system. Particularly, peroxide ligand coordinates Th cations in an unusual $\mu_{3}-\eta^{2}: \eta^{2} \eta^{2}$ bridging mode forming an infinite 1D chain decorated with sulfato ligands exhibiting simultaneously monodentate and bidentate coordination modes.
\end{abstract}

Tetravalent actinides exhibit an extremely complex and varied chemical behaviour. ${ }^{[1]}$ The chemistry of $\mathrm{Pu}(\mathrm{IV})$ has often been studied by using Th(IV) as a surrogate despite the differences in the sizes of their respective solvated ions which can be a source of significant discrepancies. On the other hand, the greater variability of the coordination number of Th(IV) compared to $\mathrm{Pu}(\mathrm{IV})$ is only very rarely addressed and remains an important challenge. ${ }^{[2]}$ The case of mixed complexes, composed of two types of polyvalent ligands such as peroxo and sulfate, is particularly interesting. The only resolved Th peroxo structure available in the literature is the tri-nuclear cluster $\left[\mathrm{Th}\left(\mathrm{O}_{2}\right) \text { (terpy) }\left(\mathrm{NO}_{3}\right)_{2}\right]_{3}$ (terpy= 2,2',6',2'-terpyridine) found to be assembled with bridging side-on/side-on $\mu-\eta^{2}: \eta^{2}$ peroxide anions coordinating Th atoms. ${ }^{[3]}$ Nevertheless, structural characterization of thorium peroxides has puzzled the coordination chemists community and the few publications that has been reported so far often deals with highly insoluble and ill-defined compounds integrating inorganic anions from the solution in the solid species. ${ }^{[4]}$ Th peroxides have been described since 1885 and have been widely used for separation purposes. ${ }^{[5]}$ Particularly,

[a] Laura Bonato, Dr. Matthieu Virot, Dr. Adel Mesbah, Dr. Xavier Le Goff, Pr. Nicolas Dacheux and Dr. Sergey I. Nikitenko ICSM, CEA, CNRS, ENSCM, Univ Montpellier, Site de Marcoule, Bat 426, 30207 Bagnols sur Ceze, France E-mail: matthieu.virot@cea.fr

[b] Dr. Thomas Dumas, Dr. Philippe Moisy

French Nuclear and Alternative Energies Commission (CEA) Nuclear Energy Division, Department of Mining and Fuel Recycling Processes (DMRC), Site de Marcoule BP17171, 30207 Bagnols sur Cèze, France

[c] Dr. Pierre Lecante

Groupe SINanO, CEMES-CNRS, 29 rue Jeanne Marvig, 31055 Toulouse Cedex 4, France

[d] Dr. Damien Prieur, Dr. Christoph Hennig

Helmholtz-Zentrum Dresden - Rossendorf, Institute of Resource Ecology, Bautzner Landstraße 400, 01328 Dresden, Germany

Supporting Information (SI) for this article is given via a link at the end of the document.

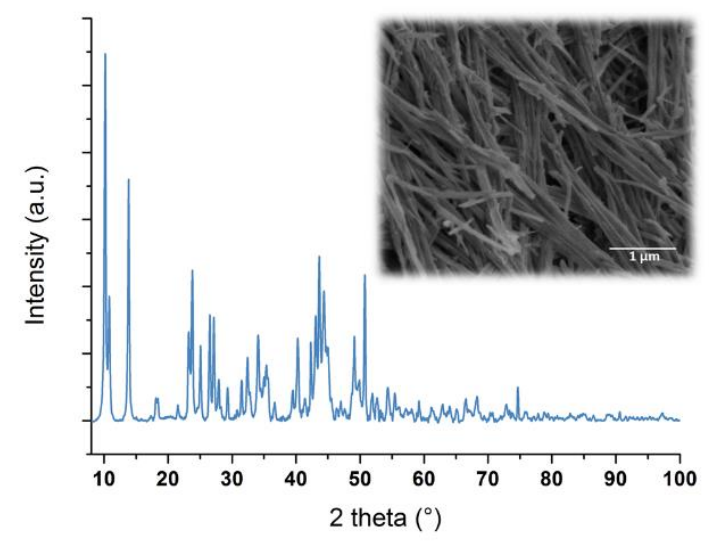

Figure 1: Powder XRD diagram (background corrected) of the synthesized $\mathrm{Th}\left(\mathrm{O}_{2}\right)\left(\mathrm{SO}_{4}\right)\left(\mathrm{H}_{2} \mathrm{O}\right)_{2}$ compound. Inset: SEM picture of the 1D fibre-like crystals. EDX analyses indicate the following chemical composition (at.\%): C: $2.9 \pm 0.6$ (from SEM carbon tapes), $0: 63.4 \pm 2.9$, S: $14.0 \pm 1.2$ and Th: $19.5 \pm 1.4$.

thorium peroxides of variable compositions have been reported to form in sulfuric acid medium. ${ }^{[4 a, 4 d, 5 a, 6]}$ The older literature reports that weakly acid conditions lead to a precipitate crystallizing in the hexagonal system ${ }^{[5 a, 6]}$ while higher acidic conditions $(>0.3 \mathrm{M})$ are proposed to form a trihydrate $\mathrm{Th}\left(\mathrm{O}_{2}\right)\left(\mathrm{SO}_{4}\right)\left(\mathrm{H}_{2} \mathrm{O}\right)_{3}$. A coordination number of 6 was proposed for this compound and the few structural interpretations have suggested an orthorhombic system comprising a bridging $\mathrm{O}-\mathrm{O}$ peroxide ligand and a bidentate chelating sulfato group. $\left.{ }^{[4 a}, 4 d, 6\right]$ The current paper describes the unprecedented structure of a mixed Th(IV) complex coordinated with peroxo and sulfate ligands.

The addition of hydrogen peroxide to a thorium sulfate solution $(0.05 \mathrm{M})$ at room temperature was found to yield a white powder composed of 1D fibre-like crystals of ca. $0.1 \mu \mathrm{m}$ diameter and a length of $4 \mu \mathrm{m}$ (Figure 1, inset). Powder X-ray diffraction pattern of the as-synthesized material (obtained on a conventional laboratory diffractometer with $\mathrm{Cu}$-Ka radiation) exhibits intense and narrow diffraction peaks which are characteristic of a highly crystalline material. Throughout the experiments, the material was observed to be very stable thus facilitating further characterizations. No correspondence with ICSD or literature was found for this product. The quality of the XRD pattern was insufficient for structure determination (e.g. Rietveld analysis) and the various attempts devoted to the preparation of a single crystal failed (crystals not big enough). Interesting structural features were nevertheless evidenced by Fourier transform infra-red (FTIR) and Raman spectroscopies. The observed vibration wavenumbers and corresponding assignments are reported in Table S1 in Supporting Information (SI). 


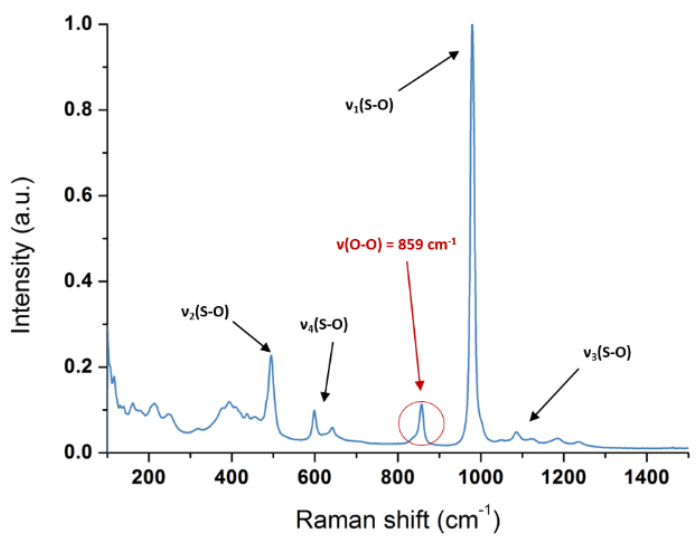

Figure 2: Normalized Raman spectrum measured on the Th peroxo sulfate attesting the coordination of peroxo and sulfato ligands $(\lambda=532 \mathrm{~nm}, 39$ $\mathrm{mW}$ ).

Both vibrational spectroscopies show the characteristic signatures of coordinated peroxide and sulfate ligands in addition to both interstitial and/or coordinated water (Figure S1, SI). Particularly, the band positioned at $859 \mathrm{~cm}^{-1}$ on the Raman spectrum (Figure 2) and the very weak one observed at $818 \mathrm{~cm}^{-1}$ on FTIR spectrum (Figure $\mathrm{S} 1, \mathrm{SI}$ ) are assigned to the $v(\mathrm{O}-\mathrm{O})$ symmetric stretching vibration mode of peroxide ligand in accordance with the bridging $\mu-\eta^{2}: \eta^{2}$ coordination mode already observed for cerium(IV), uranium(VI) and plutonium(IV) compounds. ${ }^{[2 a, 7]}$ The shift of the Raman band to lower wavenumber in comparison to free $\mathrm{H}_{2} \mathrm{O}_{2}$ (around $880 \mathrm{~cm}^{-1}$ ) can be attributed to the coordinating Th(IV) cation. ${ }^{[7 \mathrm{~d}, 8]}$ Raman bands positioned at 1128 and $1088 \mathrm{~cm}^{-1}\left(v_{3}\right) ; 979 \mathrm{~cm}^{-1}\left(v_{1}\right) ; 644$ and 601 $\mathrm{cm}^{-1}\left(v_{4}\right)$; and $496 \mathrm{~cm}^{-1}\left(v_{2}\right)$ can be assigned to sulfate ligand in agreement with the literature ${ }^{[7 \mathrm{~g}, 9]}$ and FTIR data (Figure S1, SI).$^{[4 \mathrm{~d}}$ $7 \mathrm{e}, 7 \mathrm{~g}, 9 \mathrm{a}, 9 \mathrm{c}, 10]$

Thermogravimetric analysis (TGA) illustrated in Figure S2 (SI) shows a two-step weight loss process of ca. $14.6 \%$ (between $20^{\circ} \mathrm{C}$ and $480^{\circ} \mathrm{C}$ ) and $18.6 \%$ (between $630^{\circ} \mathrm{C}$ and $1000^{\circ} \mathrm{C}$ ). These two weight losses are correlated to the endothermic peaks observed at ca. $130^{\circ} \mathrm{C}$ and $775^{\circ} \mathrm{C}$ from differential thermal analysis (DTA). The absence of weight variation below $100^{\circ} \mathrm{C}$ suggests the absence of interstitial water. The initial weight loss up to $210^{\circ} \mathrm{C}$ can be attributed to the release of peroxide and coordinated water molecules. A slow and continuous loss observed up to $480^{\circ} \mathrm{C}$ can be attributed to remaining peroxides as confirmed by a weak exothermic peak at $465^{\circ} \mathrm{C}$. The presence of a plateau between $480^{\circ} \mathrm{C}$ and $630^{\circ} \mathrm{C}$ indicates the formation of a stable intermediate compound suggested to be a thorium oxo sulfate of formula $\mathrm{ThO}\left(\mathrm{SO}_{4}\right){ }^{[11]}$ Sulfate decomposition then occurs between $630^{\circ} \mathrm{C}$ and $1000^{\circ} \mathrm{C}$. Mass spectrometry (MS) coupled with TGA (Figure S3, SI) confirmed these interpretations with the release of $\mathrm{H}_{2} \mathrm{O}$ (up to $210^{\circ} \mathrm{C}$ ), $\mathrm{O}_{2}$ (up to $480^{\circ} \mathrm{C}$ and at $695^{\circ} \mathrm{C}$ ) and $\mathrm{SO}_{2}\left(\right.$ at $695^{\circ} \mathrm{C}$ ) as summarized in Table 1. The following chemical formula can then be proposed: $\mathrm{Th}\left(\mathrm{O}_{2}\right)\left(\mathrm{SO}_{4}\right)\left(\mathrm{H}_{2} \mathrm{O}\right)_{2}$.

The solid blue curve presented in Figure 3 shows the Fourier transform (FT) of the extended X-ray absorption fine structure (EXAFS) obtained at the Th $L_{111}$-edge for the synthesized compound $\left(k^{3}\right.$-weighted EXAFS spectra is shown in Figure S4, SI). The main peak at $R-\varphi=1.9 \AA$ superimposed with a satellite
Table 1. Assignment of the mass losses observed during the TGA-DTA-MS experiments performed with the thorium peroxo sulfate compound. ${ }^{*} \% \mathrm{wt}$ is the theoretical value calculated from released molecules.

\begin{tabular}{cccc}
\hline $\begin{array}{c}\text { Temperature } \\
\left({ }^{\circ} \mathbf{C}\right)\end{array}$ & $\begin{array}{c}\text { Compound } \\
\text { (Released molecules) }\end{array}$ & \%wt $^{*}$ & $\begin{array}{c}\text { m } \\
(\mathbf{m g})\end{array}$ \\
\hline 20 & {$\left[\mathrm{Th}\left(\mathrm{O}_{2}\right)\left(\mathrm{SO}_{4}\right)\left(\mathrm{H}_{2} \mathrm{O}\right)_{2}\right]$} & - & 23.00 \\
$20-600$ & $\left(1 / 2 \mathrm{O}_{2}+2 \mathrm{H}_{2} \mathrm{O}\right)$ & 15 & 3.45 \\
600 & $\mathrm{ThO}_{\left(\mathrm{SO}_{4}\right)}$ & - & 19.55 \\
$600-1000$ & $\left(\mathrm{SO}_{2}+1 / 2 \mathrm{O}_{2}\right)$ & 18.5 & 4.25 \\
1000 & $\mathrm{ThO}_{2}$ & - & 15.30 \\
\hline
\end{tabular}

peak at $\mathrm{R}-\varphi=2.3 \AA$ corresponds to the first oxygen coordination sphere. This large peak expresses an intricate oxygen shell agreeing with the presence of peroxide, water, and sulfate ligands coordinated to the central Th atom. Two peaks noticed at $\mathrm{R}-\varphi=$ $2.8 \AA$ and $R-\varphi=3.2 \AA$ are attributed to sulfur atoms respectively evidencing both bidentate and monodentate coordination modes for sulfates. Such coordination has been already observed and discriminated on $\mathrm{U}(\mathrm{IV})$ and $\mathrm{Th}(\mathrm{IV})$ sulfato complexes giving similar FT profiles with corrected Th-S distances of $3.08 \pm 0.02$ and $3.67 \pm 0.02 \AA$ for U(IV) and $3.14 \pm 0.02$ and $3.81 \pm 0.02 \AA$ for $\mathrm{Th}(\mathrm{IV})$, respectively. ${ }^{[12]}$

Radial Distribution Function (RDF) analysis from in-lab measurements provided more structural informations (Figure S5, $\mathrm{SI})$. Because of the very high $\mathrm{Z}$ of Th compared to other elements, the experimental RDF easily compares with the Th-centered FT obtained from EXAFS, however up to several nanometres and without EXAFS specific effects (e.g. phase shift). Bonding distances are indeed observed (inset, Figure S5, SI) with a broad peak centered at $2.5 \AA$ clearly related to dispersed Th-O contributions, and a smaller one centered at $3.1 \AA$ likely related to Th-S contributions. A striking feature is the strong peak noticed at 4.1 Å obviously related to non-bonding Th-Th contributions.

A deeper understanding of the structure of this material was obtained by performing synchrotron powder $\mathrm{X}$-ray diffraction (Figure S6, SI). The indexation of the diffraction peaks, described in Experimental Section and $\mathrm{SI}$, leads to the refinement of $\mathrm{Th}\left(\mathrm{O}_{2}\right)\left(\mathrm{SO}_{4}\right)\left(\mathrm{H}_{2} \mathrm{O}\right)_{2}$ compound in an orthorhombic system in the space group Pna2 ${ }_{1}$ with four formula units per cell and lattice parameters of $a=10.2600(5) \AA, b=16.3746(7) \AA, c=4.2696(1) \AA$

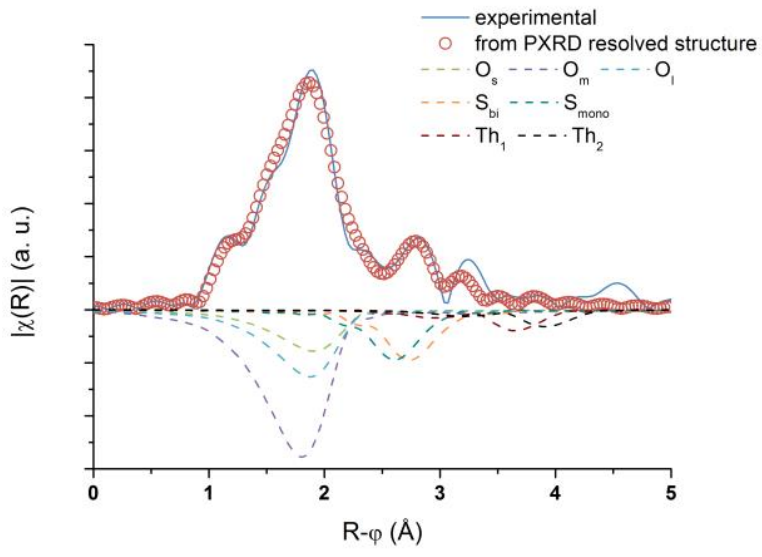

Figure 3: FT of the experimental $\boldsymbol{k}^{3}$-weighted EXAFS spectrum (solid blue curve) compared to the fitted FT derived from the structure resolved by powder synchrotron analysis (red circles). k-range fit obtained in the $2 \AA$ $1<k<13 \AA^{-1}$ range. Scattering paths for the various shells are marked with dashed lines. $\mathrm{O}_{\mathrm{s}}, \mathrm{O}_{\mathrm{m}}$, and $\mathrm{O}_{1}$ respectively stand for averaged short, medium and long distance ranges for the $O$ shell. 
and $V=717.31(5) \AA^{3}$. The asymmetric unit is composed by one Th atom surrounded by one sulfur atom and eight oxygen atoms. Four of the eight oxygen belong to the sulfate group (labelled OS), two O-atoms belong to the peroxo group (labelled OP) and the remaining two belongs to the water molecules (labelled OW). A general view of the structure down the $c$ axis is presented in Figure 4; metrical data are gathered in Table 2 (structural and refinement parameters are given in Table S2, SI).

Table 2. Selected interatomic distances in $\mathrm{Th}\left(\mathrm{O}_{2}\right)\left(\mathrm{SO}_{4}\right)\left(\mathrm{H}_{2} \mathrm{O}\right)_{2}$. OP, OS, and OW respectively stand for oxygen from peroxo group, sulfate group and water.

\begin{tabular}{|c|c|c|c|}
\hline Atom - Atom & Distance $(\AA ̊)$ & Atom - Atom & Distance $(\AA ̊ \AA)$ \\
\hline Th1 - OP1 & $2.569(5)$ & Th1 - OW1 & $2.51(3)$ \\
\hline Th1 - OP1 & $2.573(6)$ & Th1 - OW2 & $2.49(4)$ \\
\hline Th1 - OP1 & $2.378(6)$ & Th1 S1 & $3.251(5)$ \\
\hline Th1 - OP2 & $2.546(6)$ & Th1 S1 & $3.126(5)$ \\
\hline Th1 - OP2 & $2.478(7)$ & $\mathrm{S} 1-\mathrm{OS} 1$ & $1.506(4)$ \\
\hline Th1 - OP2 & $2.351(7)$ & $\mathrm{s} 1-\mathrm{OS} 2$ & $1.516(15)$ \\
\hline Th1 - OS2 & $2.42(5)$ & s1 - os3 & $1.51(3)$ \\
\hline Th1 - OS3 & $2.50(3)$ & $S 1-0 S 4$ & $1.507(19)$ \\
\hline Th1 - OS4 & $2.50(3)$ & $\mathrm{OX} 1-\mathrm{OX} 2$ & $1.486(7)$ \\
\hline
\end{tabular}

In this structure, each Th atom is coordinated to eleven oxygen atoms consisting of three OS, six OP and two OW. The formed polyhedra are connected together by edge or face sharing through the peroxo groups to form infinite polymeric chains oriented along the $c$ axis (Figure 5). The 3D cohesion is ensured by hydrogen bonds between water molecules and one oxygen from the sulfate groups. It is worth noting that the sulfate groups provide a kind of intra-chain coordination around the Th atoms. The presence of coordinated water, peroxo, monodentate and bidentate sulfate ligands, as viewed in Figure 5, agrees with the above structural hypotheses. Peroxo groups are found to be coordinated in a fairly scarce bridging $\mu_{3}-\eta^{2}: \eta^{2}: \eta^{2}$ mode recently reported in the crystal structure of lanthanide complexes $\left[\mathrm{Ln}_{4}\left(\mathrm{O}_{2}\right)_{2} \mathrm{Cl}_{8}(\mathrm{Py})_{10}\right], \mathrm{Py} \quad(\mathrm{Ln}=\mathrm{Sm}, \mathrm{Eu}, \mathrm{Gd} ; \quad \mathrm{py}=$ pyridine $)$, heterobimetallic $\mathrm{Zn}_{4} \mathrm{Ln}_{7}(\mathrm{Ln}=\mathrm{Gd}$, Dy) nano-sized clusters and $\left[\mathrm{Tb}_{3}\left(\mathrm{O}_{2}\right)(\text { pic })_{9}\right]^{2-}($ pic $=$ picolinate $)$ compound. ${ }^{[13]}$

The O-O bond length of the peroxide ligands in $\mathrm{Th}\left(\mathrm{O}_{2}\right)\left(\mathrm{SO}_{4}\right)\left(\mathrm{H}_{2} \mathrm{O}\right)_{2}$ equals ca. 1.486(7) $\AA$ which is slightly lower than those reported for $\mu_{3}$ bridged Ln-peroxo compounds $(1.52 \AA$ to $1.55 \AA$ ).$^{[13 \mathrm{~b}]}$ However, it is closer to those reported for the only two peroxide structures resolved for tetravalent actinides where the peroxide ligand exhibit $\mu_{2}-\eta^{2}: \eta^{2}$ coordination (O-O length is $1.496(6) \AA$ in the $\mathrm{Pu}(\mathrm{IV})$ peroxy-carbonate compound $\mathrm{Na}_{8} \mathrm{Pu}_{2}\left(\mathrm{O}_{2}\right)_{2}\left(\mathrm{CO}_{3}\right)_{6}, 12 \mathrm{H}_{2} \mathrm{O}$ and 1.516-1.515 $\AA$ in $\left[\mathrm{Th}\left(\mathrm{O}_{2}\right) \text { (terpy) }\left(\mathrm{NO}_{3}\right)_{2}\right]_{3}$ cluster). ${ }^{[3,}$, $\left.7 \mathrm{c}\right]$ Such difference can be attributed to the ionic radius of the tetravalent actinides $v s$. trivalent lanthanides and their related charge density. The Th-OP length in $\mathrm{Th}\left(\mathrm{O}_{2}\right)\left(\mathrm{SO}_{4}\right)\left(\mathrm{H}_{2} \mathrm{O}\right)_{2}$ ranges from 2.351(7) $\AA$ to 2.573(6) $\AA$ which agrees with the literature data observed for Th $(2.369(2) \AA)$ and Pu peroxide clusters $(2.33(1)-2.36(1) \AA)^{[3,7 c]}$ but also with $\mu_{3}$ peroxo complexes (Ln-OP ranges from 2.311(3) to 2.408(2) $\AA$ for $\mathrm{Ln}=\mathrm{Sm}$, Eu, Gd; from 2.289 to $2.501 \AA$ for $\mathrm{Ln}=\mathrm{Dy}$; and from 2.35 to $2.36 \AA$ for $L n=T b) .{ }^{[13]}$

The linking sulfate in $\mathrm{Th}\left(\mathrm{O}_{2}\right)\left(\mathrm{SO}_{4}\right)\left(\mathrm{H}_{2} \mathrm{O}\right)_{2}$ is coordinated to one Th atom in bidentate coordination mode with a Th-S distance of $3.126(5) \AA$ and to a neighbouring Th atom in monodentate

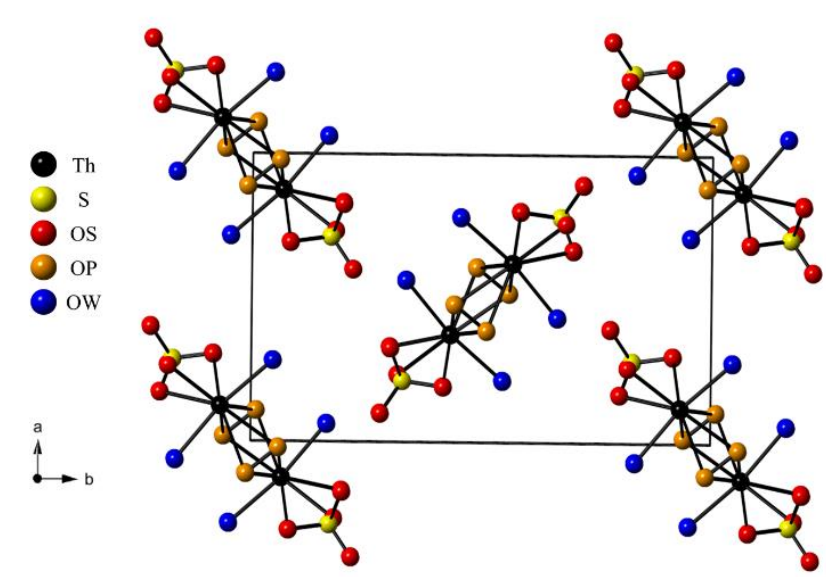

Figure 4: Arrangement of the asymmetric unit $\mathrm{Th}\left(\mathrm{O}_{2}\right)\left(\mathrm{SO}_{4}\right)\left(\mathrm{H}_{2} \mathrm{O}\right)_{2}$ along the [001] direction

coordination mode with a Th-S distance of 3.251(5) A. Compared to other Th sulfate compounds, $\operatorname{Th}\left(\mathrm{O}_{2}\right)\left(\mathrm{SO}_{4}\right)\left(\mathrm{H}_{2} \mathrm{O}\right)_{2}$ shows a smaller difference between Th-S distances for both coordination modes. Simultaneous bidentate and monodentate coordination for sulfato ligands has been reported by Hennig et al. for U(IV) (distances of $3.08 \pm 0.02$ and $3.67 \pm 0.02 \AA$, respectively) and $\mathrm{Th}(\mathrm{IV})(3.14 \pm 0.02$ and $3.81 \pm 0.02 \AA$, respectively) sulfato complexes. ${ }^{[12]}$ Arutyunyan and Porai-Koshits reported both coordination modes in $\mathrm{K}_{4}\left[\mathrm{Th}\left(\mathrm{SO}_{4}\right)_{4}\left(\mathrm{H}_{2} \mathrm{O}\right)_{2}\right]$ with distances of 3.119 $\AA$ and $3.715 \AA,{ }^{[14]}$ respectively. Habash and Smith reported distances of $3.173 \AA$ and $3.741 \AA$, respectively, in $\mathrm{Cs}_{2} \mathrm{Th}\left(\mathrm{SO}_{4}\right)_{3}\left(\mathrm{H}_{2} \mathrm{O}\right)_{2}$ compound. ${ }^{[15]}$ The shorter Th-S distance in $\mathrm{Th}\left(\mathrm{O}_{2}\right)\left(\mathrm{SO}_{4}\right)\left(\mathrm{H}_{2} \mathrm{O}\right)_{2}$ is related to the intra-chain coordination which brings monodentate sulfate closer to Th centers. The resulting Th$\mathrm{O}-\mathrm{S}$ angle for monodentate coordination is about $107.30^{\circ}$ against $137.19^{\circ}$ measured for instance in $\mathrm{K}_{4}\left[\mathrm{Th}\left(\mathrm{SO}_{4}\right)_{4}\left(\mathrm{H}_{2} \mathrm{O}\right)_{2}\right]^{[14]}$ The flexibility of the Th-O-S angle in monodentate coordination allows a wide variation of Th-S distances.

The validity of the structural model is supported by simulating the experimental EXAFS signal (Figure 3 and Table 3 ). Scattering paths in a R-range from 0 to $4.3 \AA$ A were included and coordination numbers were maintained strictly identical to those derived from XRD. Interatomic distances and Debye-Waller factors (DWF) were adjusted using a global floating parameter for each shell. The corresponding fit (red circles in Figure 3 ) is in very good agreement with the experimental EXAFS spectrum (R-factor $<5 \%)$ thus strengthening the validity of the proposed crystal structure. In detail, the 11 oxygen atoms observed in the first shell

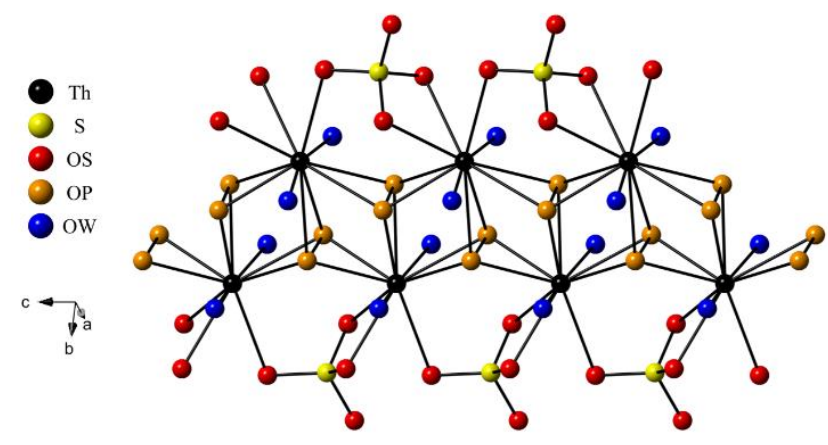

Figure 5: Arrangement of the asymmetric unit $\mathrm{Th}\left(\mathrm{O}_{2}\right)\left(\mathrm{SO}_{4}\right)\left(\mathrm{H}_{2} \mathrm{O}\right)_{2}$ forming polymeric chains along the $\mathrm{c}$ axis and evidencing the presence of bridging $\mu_{3}-\eta^{2}: \eta^{2}: \eta^{2}$ peroxo ligands, coordinated water molecules, and simultaneous monodentate and bidentate sulfato ligands. 
are positioned at distances ranging from $2.29 \AA$ to $2.55 \AA$. The second shell contains one short $S$ atom from a bidentate sulfate ligand at $3.13 \AA$ and a longer one at $3.23 \AA$ from a monodentate sulfate group.

It is noteworthy that Th atoms located in the third coordination shell (two at $3.997 \AA$ and two at $4.270 \AA$ ) are barely observed in both the experimental and simulated EXAFS spectra (Figure 3 ). Such counter-intuitive effect, already observed during the characterization of $\mathrm{ThSiO}_{4}$ nanoparticles, has been ascribed to destructive interferences generated by the contribution of different Th-Th distances. ${ }^{[16]}$ This effect is illustrated in Figure S7 (SI) where the phases of the Th-Th scattering paths obtained from the synchrotron resolved structure are found to be opposite on the EXAFS signal. This phenomenon prevents a correct extraction of structure parameters from the Th scattering contribution. The experimental observation of Th-Th distances could be overcome by using $\mathrm{X}$-ray scattering where all the individual contributions of atom pairs are summed for a global scattering signal, with strong emphasis on pairs involving Th (Figure S5, SI). The good global agreement between both experimental and simulated RDF also confirms its validity. Since the strong amorphous background clearly observed on non-corrected XRD data (Figure S6, SI) also fully contributes to the RDF, this agreement is also a proof that the studied compound includes only one structural phase, however with different degrees of crystallization.

Table 3. EXAFS structural parameters calculated according to the synchrotron resolved structure. R-factor $4.5 \%$, ${ }^{*}$ fixed value, ${ }^{*}$ averaged value, $\mathrm{S}_{0}{ }^{2}=1.0, \mathrm{CN}$ : coordination number, $\sigma^{2}$ : Debye-Waller factor, $\Delta \mathrm{E}_{0}=4.8 \mathrm{eV}$. Os, $\mathrm{O}_{\mathrm{m}}$, and $\mathrm{O}$ respectively stand for averaged short, medium and long distance ranges for the $\mathrm{O}$ shell.

\begin{tabular}{cccc}
\hline Paths & $\mathbf{C N}^{\boldsymbol{*}}$ & $\boldsymbol{\sigma}^{\mathbf{2}}\left(\boldsymbol{\AA}^{2}\right)$ & $\mathbf{R}(\mathbf{A})$ \\
\hline $\mathrm{O}_{s}$ & 2 & $0.010(3)$ & $2.29(2)^{\#}$ \\
$\mathrm{O}_{\mathrm{m}}$ & 6 & $0.010(3)$ & $2.41(2)^{\#}$ \\
$\mathrm{O}_{\mathrm{l}}$ & 3 & $0.010(3)$ & $2.55(2)^{\#}$ \\
\hline $\mathrm{S}_{\text {bid }}$ & 1 & $0.003(2)$ & $3.13(3)$ \\
$\mathrm{S}_{\mathrm{mon}}$ & 1 & $0.003(2)$ & $3.23(3)$ \\
\hline $\mathrm{Th}_{1}$ & 2 & $0.014(5)$ & $3.91(10)$ \\
$\mathrm{Th}_{2}$ & 2 & $0.014(5)$ & $4.17(10)$ \\
\hline
\end{tabular}

The synthesis and structural characterization of this unprecedented Th peroxo sulfate polymerizing within the form of stable 1D fibre-like crystals, clarify old discussions and contributes in filling the knowledge gap available on tetravalent actinide peroxo compounds. Particularly, the crystal structure of $\mathrm{Th}\left(\mathrm{O}_{2}\right)\left(\mathrm{SO}_{4}\right)\left(\mathrm{H}_{2} \mathrm{O}\right)_{2}$ puzzled actinide scientists for more than a century and its characterization can be considered as milestone achievement that opens new investigation routes for the synthesis and understanding of other actinide peroxides. The observed rare 11-fold coordination of Th cations in this structure reveals a striking difference with the known actinide coordination geometries.

\section{Acknowledgements}

The authors gratefully acknowledge Mohamed Ruwaid Rafiuddin for useful discussion.

\section{Experimental Section}

Caution! ${ }^{232}$ Th is an $\alpha$-emitting radionuclide and standard precautions should be followed for handling these radioactive materials.

Synthesis. An aqueous solution of Th at $0.0135 \mathrm{M}$ was prepared by dissolving $77 \mathrm{mg}$ of $\mathrm{Th}\left(\mathrm{NO}_{3}\right)_{4} .5 \mathrm{H}_{2} \mathrm{O}$ in $9 \mathrm{~mL}$ of $0.05 \mathrm{M}$ sulfuric acid. $1 \mathrm{~mL}$ of $2.7 \mathrm{M} \mathrm{H}_{2} \mathrm{O}_{2}$ diluted in $0.05 \mathrm{M}$ sulfuric acid was rapidly added to the Th solution. A white precipitate is formed one hour after the addition of the hydrogen peroxide. After centrifugation and washing with water, this precipitate is dried at room temperature under Ar before characterizations.

Extended X-Ray Absorption Fine Structure (EXAFS) analysis. The powdered compound was finely ground and mechanically mixed with boron nitride. EXAFS measurements were performed at the HZDRoperated Rossendorf beamline (European Synchrotron Radiation Facility, Grenoble, France) using a $\mathrm{Si}(111)$ double-crystal monochromator. Experimental spectra were recorded at Th $\mathrm{L}_{\text {III }}$ edge in fluorescence mode using a 13-element $\mathrm{Ge}$ detector at room temperature and pressure. EXAFS data were analysed using Athena and Artemis softwares from the IFEFFIT package. ${ }^{[17]}$

X-ray structural analysis. $\mathrm{Th}\left(\mathrm{O}_{2}\right)\left(\mathrm{SO}_{4}\right)\left(\mathrm{H}_{2} \mathrm{O}\right)_{2}, 396$ g.mol ${ }^{-1}$; white precipitate; orthorhombic system; Pna2 1 space group; $V=717.31(5) \AA^{3}$; $\rho_{\text {calcd }}=3.631 ; Z=4 ; a=10.2600$ (5) $\AA, b=16.3746(7) \AA$ and $c=4.2696(1) \AA$ Synchrotron powder $\mathrm{X}$-ray diffraction data were recorded at the Rossendorf beamline - BM20 (ESRF) using a Pilatus $3 \times 2 \mathrm{M}$ detector (sample-detector: $39.9 \mathrm{~cm} ; \lambda=0.77490 \AA$; $\mathrm{Si}(111)$ double-crystal monochromator). The first 30 peaks of the pattern were indexed using the $\mathrm{X}$-Cell algorithm incorporated in the Reflex program of materials studio. ${ }^{[18]}$ The best solution was proposed in the orthorhombic crystal system in the space group Pna2 1 with unit cell parameters of $a=10.2725 \AA, b=16.3908$ $\AA$ and $\mathrm{c}=4.2761 \AA$. The Le Bail treatment of the powder pattern led to $\mathrm{a}$ satisfactory refinement with $R_{p}=0.014$ and $R_{w p}=0.023$. The obtained profile parameters were introduced in the Fox program to solve the crystal structure in the direct space methods where the sulfate groups were introduced as a rigid body. ${ }^{[19]}$ After few cycles, the proposed solution was successfully refined without hydrogen atoms by the Rietveld method using the Fullprof suite program. ${ }^{201}$

A full description of the characterization techniques and procedures is available in the Supporting Information. Further details on the crystal structure investigation(s) may be obtained from the Fachinformationszentrum Karlsruhe, 76344 Eggenstein-Leopoldshafen, Germany (fax: (+49)7247-808-666; e-mail: crysdata@fiz-karlsruhe.de), on quoting the depository number CSD 1904119.

Keywords: thorium $\cdot$ peroxide $\cdot$ sulfate $\cdot$ spectroscopic techniques • structure elucidation

[1] The Chemistry of the Actinide and Transactinide Elements, Springer Netherlands, 2011

[2] a) J. Qiu, P. C. Burns, Chem. Rev. 2013, 113, 1097-1120; b) K. E. Knope, L. Soderholm, Chem. Rev. 2013, 113, 944-994; c) J. Lin, J. N. Cross, J. Diwu, N. A. Meredith, T. E. Albrecht-Schmitt, Inorg. Chem. 2013, 52, $4277-$ 4281.

[3] S. S. Galley, C. E. Van Alstine, L. Maron, T. E. Albrecht-Schmitt, Inorg Chem. 2017, 56, 12692-12694.

[4] a) V. Raman, G. V. Jere, Indian J. Chem. 1973, 11, 1318-1319; b) G. L. Johnson, M. J. Kelly, D. R. Cuneo, J. Inorg. Nucl. Chem. 1965, 27, 1787 1791 ; c) G. V. Jere, M. T. Santhamma, Journal of the Less-Common Metals 1977, 55, 281-284; d) V. Raman, G. V. Jere, Indian J. Chem. 1973, 11, 31 34; e) R. A. Hasty, J. E. Boggs, J. Less-Common Met. 1964, 7, 447-452; f) R. A. Hasty, J. E. Boggs, J. Inorg. Nucl. Chem. 1971, 33, 874-876.

[5] a) M. Wickleder, B. Fourest, P. Dorhout, in The Chemistry of the Actinide and Transactinide Elements, Springer, Dordrecht ed. (Eds.: L. Morss, N. Edelstein, J. Fuger), pp. 52-160; b) A. d. Abrão, A. A. de Freitas, F. M. S. de Carvalho, J. Alloys Compd. 2001, 323-324, 53-56.

[6] G. T. Seaborg, The transuranium elements : research papers. 1. Papers 1.1 to 6.39 , McGraw-Hill, 1949

[7] a) W. P. Griffith, T. D. Wickins, J. Chem Soc. A 1968, 397-400; b) B. T. McGrail, G. E. Sigmon, L. J. Jouffret, C. R. Andrews, P. C. Burns, Inorg Chem. 2014, 53, 1562-1569; c) W. Runde, L. F. Brodnax, G. S. Goff, S. M Peper, F. L. Taw, B. L. Scott, Chem. Commun. 2007, 1728-1729; d) L. E. 
Sweet, J. F. Corbey, F. Gendron, J. Autschbach, B. K. McNamara, K. L. Ziegelgruber, L. M. Arrigo, S. M. Peper, J. M. Schwantes, Inorg. Chem. 2017, 56, 791-801; e) N. P. Pook, A. Adam, Z. Anorg. Allg. Chem. 2014 640, 2931-2938; f) S. Bastians, G. Crump, W. P. Griffith, R. Withnall, J. Raman Spectrosc. 2004, 35, 726-731; g) C. R. Bhattacharjee, M. K. Chaudhuri, R. N. D. Purkayastha, Inorg. Chim. Acta 1989, 160, 147-152.

[8] A. A. Mikhaylov, A. G. Medvedev, A. V. Churakov, D. A. Grishanov, P. V. Prikhodchenko, O. Lev, Chem-Eur J 2016, 22, 2980-2986.

[9] a) K. E. Knope, R. E. Wilson, S. Skanthakumar, L. Soderholm, Inorg. Chem 2011, 50, 8621-8629; b) K. Ben Mabrouk, T. H. Kauffmann, H. Aroui, M. D. Fontana, J. Raman Spectrosc. 2013, 44, 1603-1608; c) G. V. Jere, G. D. Gupta, J. Inorg. Nucl. Chem. 1970, 32, 537-542; d) Ananthanarayana.V, Z. Phys. 1962, 166, 318-327.

[10] a) C. R. Bhattacharjee, J. Coord. Chem. 1995, 34, 215-220; b) G. V. Jere, C. C. Patel, Can. J. Chem. 1962, 40, 1576-1578; c) K. Nakamoto, Infrared and Raman Spectra of Inorganic and Coordination Compounds: Part B: Applications in Coordination, Organometallic, and Bioinorganic Chemistry, Fifth ed., New York, 1997.

[11] V. Raman, G. V. Jere, Indian J. Chem. 1973, 11, 476-477.

[12]C. Hennig, K. Schmeide, V. Brendler, H. Moll, S. Tsushima, A. C. Scheinost, Inorg. Chem. 2007, 46, 5882-5892.

[13] a) W. J. Gee, J. G. MacLellan, C. M. Forsyth, B. Moubaraki, K. S. Murray P. C. Andrews, P. C. Junk, Inorg. Chem. 2012, 51, 8661-8663; b) B. Neumuller, F. Weller, T. Grob, K. Dehnicke, Z. Anorg. Allg. Chem. 2002 $628,2365-2371$; c) H. S. Ke, X. H. Lu, W. Wei, W. Y. Wang, G. Xie, S. P. Chen, Dalton Trans. 2017, 46, 8138-8145.

[14] É. G. Arutyunyan, M. A. Porai-Koshits, J Struct Chem+ 1963, 4, 251-252.

[15] J. Habash, A. J. Smith, J. Crystallogr. Spectrosc. Res. 1992, 22, 21-24.

[16] C. Hennig, S. Weiss, D. Banerjee, E. Brendler, V. Honkimäki, G. Cuello, A Ikeda-Ohno, A. C. Scheinost, H. Zänker, Geochim. Cosmochim. Acta 2013, 103, 197-212.

[17] a) W. Matz, N. Schell, G. Bernhard, F. Prokert, T. Reich, J. Claussner, W. Oehme, R. Schlenk, S. Dienel, H. Funke, F. Eichhorn, M. Betzl, D. Prohl, U. Strauch, G. Huttig, H. Krug, W. Neumann, V. Brendler, P. Reichel, M. A Denecke, H. Nitsche, J. Synchrotron Rad. 1999, 6, 1076-1085; b) B. Ravel, M. Newville, J. Synchrotron Rad. 2005, 12, 537-541.

[18] M. A. Neumann, J. Appl. Crystallogr. 2003, 36, 356-365.

[19] a) V. Favre-Nicolin, R. Cerny, J. Appl. Crystallogr. 2002, 35, 734-743; b) R. Cerny, V. Favre-Nicolin, Powder Diffr. 2005, 20, 359-365.

[20] C. Frontera, J. Rodriguez-Carvajal, Physica B 2003, 335, 219-222. 
Entry for the Table of Contents (Please choose one layout)

Layout 1:

\section{COMMUNICATION}

The structural characterization of an original Th peroxo sulfate dihydrate crystallizing at room temperature in the form of stable 1D polymeric microfibers is described.

$\mathrm{Th}\left(\mathrm{O}_{2}\right)\left(\mathrm{SO}_{4}\right)\left(\mathrm{H}_{2} \mathrm{O}\right)_{2}$ crystallizes in the $\mathrm{Pna}_{1}$ space group of the orthorhombic system. Peroxide ligands coordinate Th cations with a scarce $\mu_{3}-\eta^{2}: \eta^{2}: \eta^{2}$ bridging mode forming infinite $1 \mathrm{D}$ chains decorated with simultaneous monodentate and bidentate sulfato ligands.

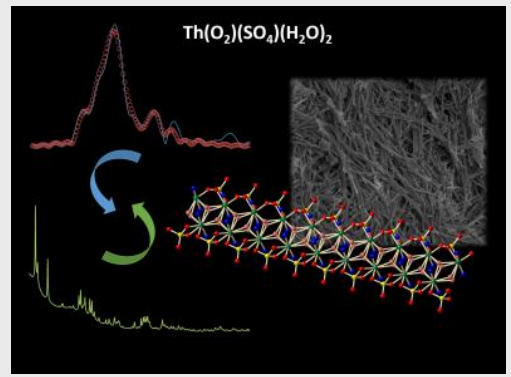

Laura Bonato, Matthieu Virot, * Thomas Dumas, Adel Mesbah, Pierre Lecante, Damien Prieur, Xavier Le Goff, Christoph Hennig, Nicolas Dacheux, Philippe Moisy, and Sergey I. Nikitenko, Corresponding Author(s)*

Page No. - Page No.

Deciphering the Crystal Structure of a Scarce 1D Polymeric Thorium Peroxo Sulfate

Layout 2:

\section{COMMUNICATION}

